\title{
Hasta Güvenliği İletişim Aracına Uygun Nöbet Teslim Sürecinin Geliştirilmesi ve Değerlendirilmesi
}

\author{
Gülçin CENGİ', (iD) Şeyda SEREN İNTEPELER ${ }^{2}$
}

${ }^{1}$ Uzman Hemşire, Dokuz Eylül Üniversitesi Sağlık Bilimleri Enstitüsü, İzmir, Türkiye.

2Prof. Dr., Dokuz Eylül Üniversitesi Hemşirelik Fakültesi Hemşirelikte Yönetim Anabilim Dalı, İzmir, Türkiye.

\section{$\ddot{O} z$}

Giriş: Sağlık hizmetlerinde kullanılan ve önerilen SBAR (Situation, Background, Assessment, Recommendation - Durum, Tibbi Öykü, Değerlendirme, Öneriler) iletişim tekniğinin, hasta teslimlerinde kullanılmasının iletişime bağlı tıbbi hataların önlenmesinde etkili olduğu belirtilmektedir. Amaç: Bu çalışmanın amacı, hasta güvenliğinde kullanılan ve önerilen iletişim aracı SBAR tekniğine uygun olarak geliştirilen nöbet teslim formu ile hasta tesliminin gerçekleştirilmesi ve değerlendirilmesidir. Yöntem: Eylem araştırması olarak yürütülen araştırmanın örneklemine İzmir'de bulunan bir üniversite hastanesinin iki cerrahi, üç dahili kliniğinde çalışan 55 hemşire alınmıştır. Veriler, tanıtıcı ve çalışma durumu bilgi formu, SBAR teslim formu, SBAR geri bildirim formlarıyla 15 Aralık 2018- 15 Eylül 2019 tarihleri arasında toplanmıştır. Verilerin değerlendirilmesinde sayı, yüzdelik ve frekans olarak tanımlayıcı istatistikler kullanılmıştır. Bulgular: SBAR teslim formunun Durum (S) bölümü \%98.9, Tıbbi Öykü (B) bölümü \%96.1, Değerlendirme (A) bölümü \%75.8 ve Öneri (R) bölümü \%91.5 oranında doldurulmuştur. Hemşirelerin \%86.4'i, nöbet tesliminde SBAR iletişim aracının zaman kaybettirdiğini düşündüğünü bildirmiştir. Bu oran formu dokuz ay kullanan klinikte \%53.8 olarak belirlenmiştir. SBAR iletişim aracı kullanmanın nöbet teslimlerine olumlu bir katkı getirmediğini düşünen hemşire oranı \%86.4 olarak bulunmuş, dokuz ay kullanan klinik değerlendirildiğinde ise bu oranın \%53.8 olduğu saptanmıştır. Hemşirelerin \%59.4'i ve dokuz ay süreyle kullanan klinik hemşirelerinin \%84.6'i SBAR iletişim aracı kullandığı dönemde hiç istenmeyen (advers) olay yaşamadığını bildirmiştir. Sonuç: Çalışmada teslim sürecinde iletişim aracı olarak SBAR tekniği kullanılmış ancak iş yoğunluğu nedeniyle hemşirelerin büyük çoğunluğu formu kullanmaya devam etmek istemediği sonucuna ulaşılmıştır. Yönetici ve klinik hemşirelere, hasta güvenliğinde etkili iletişimi sağlayabilmek için SBAR gibi standardize edilmiş iletişim araçlarını kullanmaları ve hemşireleri bu yönde cesaretlendirmeleri önerilebilir. Değişim sürecinin başlatılması ve düzenli eğitimlerin verilmesi yararlı olacaktır.

Anahtar kelimeler: Hasta Güvenliği, Hemşire Nöbet Teslimi, İletişim Hataları, SBAR İletişim Aracı.

\begin{abstract}
Improving And Evaluating Nurse Handover Process By Using Patient Safety Communication Tool

Background: It is stated that the SBAR (Situation, Background, Assessment, Recommendation) communication technique used and recommended in healthcare services is effective in preventing communication-related medical errors. Purpose: The aim of this study to improve and evaluate the nurse handover process by using handover form which is used in patient safety and proposed according to SBAR technique. Method: An action research study was employed. The sample consisted of 55 registered nurses working in three surgical and three internal wards of a university hospital located in İzmir. The data was collected with introductory and working status information form, SBAR handover form and SBAR feed-back form in between December 15, 2018- September 15, 2019. Descriptive statistics (frequency/percentage, arithmetic mean) were used in data evoluation. Results: Situation (S) part of SBAR handover form has been filled with a ratio of 98.9\%, Background (B) part; 96.1\%, Assessment (A) part; 75.8\% and Recommendation (R) part; 91.5\%.Nurses participating in this study stated that the use of the SBAR communication tool lost time on handover with the percentage of $86.4 \%$. This ratio in the experimented clinic was $53.8 \%$. $86.4 \%$ of sample reported that using the SBAR communication tool did not contribute positively to nurse handovers, in the experimented clinic $53.8 \%$ of sample thought this. $59.4 \%$ nurses and $84.6 \%$ experimented clinic nurses reported that there were no adverse events when using the SBAR communication tool. Conclusion: In this study, the SBAR technique was used as a communication tool in the handover process, but it was concluded that the majority of the nurses did not want to continue using the form due to the workload. Managers and clinical nurses can be advised to use standardized communication tools such as SBAR in order to ensure effective communication in patient safety and to encourage nurses in this direction. It would be beneficial to initiate the change process and to provide regular trainings.
\end{abstract}

Key words: Patient Safety, Nursing Handover, Communication Errors, SBAR Communication Tool.

Geliş Tarihi / Received: 27.01.2021 Kabul Tarihi / Accepted: 16.09.2021

Correspondence Author: Hemşire, Dokuz Eylül Üniversitesi Sağlı Bilimleri Enstitüsü, İzmir, Türkiye. E-posta: gulcin.oztoprak@gmail.com

Cite This Article: Cengiz G, Seren İntepeler Ş. Hasta Güvenliği İletişim Aracına Uygun Nöbet Teslim Sürecinin Geliştirilmesi ve Değerlendirilmesi. Dokuz Eylül Üniversitesi Hemşirelik Fakültesi Elektronik Dergisi. 2021; 14(4): 404- 412 
$\mathbf{H}$ asta güvenliği; hastaları, sağlık bakımı ile ilişkili tıbbi hatalardan korumak şeklinde tanımlanmaktadır (1). Tıbbi hatalar, tanı hataları, hastane enfeksiyonları, düşmeler, iletişim hataları ve ilaç hataları olarak karşımıza çıkmaktadır (2). Sağlık bakımında oluşan iletişim hatalarının ciddi, genellikle ölümcül sonuçları olabilmektedir (3). Uluslararası Birleşik Komisyonu (Joint Commission International-JCI) 2014 istenmeyen olay raporunda, hataların kök neden analizlerinde iletişim üçüncü sırada yer almaktadır (4). Harvard Üniversitesi Risk Yönetim Vakfı (CRICO)'nın yayımladığı rapora göre; 2009-2013 yılları arasında açılan malpraktis davalarının \%30'unun iletişim kaynaklı olduğu görülmüştür. Bu davaların \%49'u ekip içi iletişim hatalarından kaynaklanmaktadır (5). Ülkemizde Sağlık Bakanlığı verilerinde tıbbi hataların kaynağının büyük oranda iletişim olduğu belirtilmektedir (6). Aynı zamanda ulusal hata bildirim sistemi olan 'Güvenlik Raporlama ve Hata Sınıflandırma Sistemleri' verilerine göre iletişim kaynaklı hataların \%6.5 olduğu görülmektedir (7). Etkisiz iletişime bağlı önlenebilir hataların artmasından dolayı 2006'da JCI etkili iletişimi, ulusal güvenlik hedefleri arasına almış̧ır (8). Aynı zamanda Dünya Sağlık Örgütü (DSÖ), 2006'dan bu yana hasta teslimlerindeki iletişime, hasta güvenliği girişimlerinde ilk beş sirada yer vermektedir (9). Starmer ve ark. (2013), iletişim aracı uygulayarak yaptıkları çalışmada, önlenebilir advers olayların girişim sonrası $\% 3.3$ ’ten \%1.5'e düştüğü gözlenmiştir (10).

İletişime bağlı hasta güvenliği sorunlarının yaşanmaması açısından hasta teslimleri önem arz etmektedir. Hasta teslimlerinde hasta ile ilgili bilgiler sistematik bir süreçte vardiyası sona eren hemşire tarafindan yeni vardiyaya başlayacak olan hemşireye iletilmektedir (11). Ülkemizde hastaların sağlık çalışanları arasında güvenli bir şekilde devredilmesinin sağlanması Sağlıkta Kalite Standartları (SKS) arasında yer almaktadır. SKS, tüm hastaneler için bir kılavuz olarak kullanılmakta ve standart bir metin olarak ortak dil yaratmaktadır. (6). Bu açıdan hasta teslimleri hasta güvenliği uygulamalarında önemli bir yere sahiptir. Alanyazındahasta teslimi için en sık SBAR (Situation, Background, Assessment, Recommendation - Durum, Trbbi Öykü, Değerlendirme, Öneriler), I PASS the BATON (Introduction, Patient, Assessment, Situation, Safety concerns, Background, Actions, Timing, Ownership, Next - Tanıtma, Hasta, Değerlendirme, Durum, Güvenlik kaygıları, Öykü, Eylem, Zamanlama, Sorumluluk, Sonraki), 5P's (Patient, Plan, Purpose, Problems, Precautions - Hasta, Planlama, Amaç, Sorunlar, Önlemler), HANDOFFS (Hello, Assessment, Necessary Patient Information, Danger or Risks, Occurrence, Framework, Future Recommendations, Seek Questions Merhaba, Değerlendirme, Önemli Hasta Bilgileri, Tehlike veya Riskler, Mevcut Tanı, Hasta Öyküsü, Öneriler, Soru Sorun) gibi profesyonel iletişim teknikleri kullanılmaktadır (12).

Dünya Sağlık Örgütü de bu kapsamda hasta güvenliğinde iletişimi geliştirmek için SBAR tekniğinin kullanılmasını önermektedir (1). Aynı zamanda Sağlık Bakımını Geliştirme Enstitüsü (Institute for Healthcare Improvement-IHI)'nün 2006 yayınında, hasta güvenliği için önerdiği rehber adımlarından biri de ekip içi iletişimin geliştirilmesi ve SBAR iletişim aracının kullanımının sağlanmasıdır(13).

SBAR, hastanın durumuyla ilgili bilginin bir sağlık çalışanından diğer sağlık çalışanına iletilmesini sağlayan, kanıta dayalı olarak kullanılan etkin bir iletişim tekniğidir. Teknik olarak baş harfler kullanılarak hatırlatıcı modelde bir araç olan SBAR dört bölümden oluşmaktadır $(12,14)$ :

S- Situation/Durum: Hastanın mevcut durumu nedir?

B- Background/Tıbbi Öykü: Klinik geçmişi ve yatış sebebi nedir?

A- Assessment/Değerlendirme: Problemin ......olduğunu düşünüyorum.

R- Recommendation/Öneri:Ben ....̈neririm.

Aşağıda SBAR iletişim aracıyla ilgili bir hemşire-hemşire hasta teslim örneği yer almaktadır $(12,14)$.

- Hasta A, 74 yaşında. Acil servisten iki gün önce yatırılmış. Kol bandı acil servise ait kalmış, üstelik beyaz, parasetamol alerjisi mevcut. Ben değiştirmesi için yönlendirdim ( $\mathbf{S}=\mathbf{D u r u m})$

- Akut arter tıkanıklığı tanısıyla yatıyor, ek diyabet ve hipertansiyon tanısı da mevcut. Bugün operasyon için aç bekliyor. $50 \mathrm{ml} / \mathrm{s} \mathrm{SF}$ infüzyonu başladım. Önceden kullandığı asetilsalisilik asit tb PO tedavisi kesildi, yerine enoxaparin sodyum $0.6 \mathrm{ml} \mathrm{SC}$ tedavisi başlandı, operasyon planlandığı için dün akşamki dozunu Dr. A. önerisiyle atladım (B=Tıbbi Öykü)

- Hastanın kan basıncı yüksek seyretti. Kan şekeri izlemi normaldi, sabah aç olduğu için insülinini atladım. Sol alt ekstremitede şiddetli ağrısı mevcut. Dr. A. önerisiyle analjezik uyguladım, kan basıncı da normale geriledi, hastanın sol alt ekstremitesi soğuk ve nabızları elle palpe edilemiyor, ssıtmak için sardım, mobilizasyonu ve hareketi oldukça kısıtll, hasta da kaşektik görünümde, basınç yarası yönünden risk grubunda, değerlendirme formu çıkardım (A=Değerlendirme)

- Yaşam bulguları $6 * 1$ izlenebilir, kan şekeri takibi $4 * 1$, hastanın mobilizasyonu kısıtlı basınç bölgelerini değiştirmek amaçlı 6*1 masaj/pozisyon planlabilir. Nörovasküler izlemi $12 * 1$, sol alt ekstremite yakın takip gerektiriyor ( $R=$ Öneri).

SBAR iletişim aracının, ramak kala ve tıbbi hataları önlediği, hasta teslim süresini kısalttığı ve çalışan memnuniyetini arttırdığı, beklenmeyen ölümleri ve istenmeyen olayları azalttığı, diğer ekip üyeleri ile olan iletişimi güçlendirdiği bilinmektedir (15-20). SBAR iletişim aracı, hasta teslimlerini belirgin olarak kolaylaştırmaktadır. Bir sağlık kuruluşunun derlenme ünitesinde yapılan bir çalışmada SBAR iletişim aracını kullanmak teslim süresini 40 dakikadan 10 dakikaya düşürmüş ve kurum fazla mesailerden iki ay içinde 8000 dolar kar elde etmiştir (19).

Riesenberg ve ark. (2009), iletişim yöntemi olarak 24 anımsatıcının incelendiği çalışmalardan oluşan sistematik derlemede, çoğunlukla (\%69.6) SBAR tekniğinin kullanıldığını saptamışlardır (21). Bir diğer çalışmada, hasta teslimlerinde SBAR iletişim tekniğini kullanan hemşirelerin ekip içi iletişimin daha açık olduğunu düşündüğü, SBAR kullanımıyla daha kolay hasta teslimi görevini tamamladığı ve hasta bakım planını kolaylaştıran bütün bilgilere hakim olduğu sonucuna varılmıştır (22). ABD'de yapılan çalışmalarda, hemşirelerin iletişimde iyi bir araç olarak SBAR 
tekniğini seçtikleri ve teslimlerde SBAR kullanımından memnun oldukları belirlenmiştir $(23,24)$. İsveç’te bir hastanenin üç cerrahi kliniğinde yapılan yarı deneysel çalışmada hemşirelerin çoğunluğu SBAR tekniğini çok yararlı bulmuş, çalışma sonuç olarak SBAR tekniğinin sağlık ekip üyeleri arasında hasta güvenliğini arttıran iyi bir iletişim aracı olduğunu göstermiştir (25). Bir başka çalışmada SBAR kullanımından sonra yapılan karşılaştırma sonucunda iletişim hatalarına bağlı tıbbi hata oranının \%31'den \%11'e düştüğü gözlenmiştir (17). O'Connell ve ark. (2017), yaptıkları çalışmada; hasta teslim yapısını incelemiş, hasta teslimlerinin SBAR kullanımından sonra süre olarak beş dakikanın altına düştüğü sonucuna ulaşmışlardır (26). Aynı çalışmada SBAR iletişim aracından hemşirelerin \%91.2'si memnun olduklarını, \%56.9'u iletişim hatalarını azalttığına inandıklarını ifade etmiş̧ir.

Tüm çalışmalar incelendiğinde, SBAR iletişim aracı kullanılmasının, kullanıcılar tarafından benimsendiği, teslimlerin kısa sürede gerçekleştirilebildiği, en önemlisi de tıbbi hataları azaltmada etkili bir yöntem olduğu sonucuna ulaşılmıştır. Ancak ülkemizde SBAR tekniğinin iletişim hataları üzerine etkisini araştıran sınırlı sayıda çalışma bulunmaktadır.

\section{Araştırmanın amacı}

Araştırmanın amacı, hasta güvenliğinde kullanılan ve önerilen iletişim aracı SBAR tekniğine uygun olarak oluşturulan nöbet teslim formu ile hasta tesliminin gerçekleştirilmesi ve değerlendirilmesidir.

\section{Araştırma sorulart}

- Hemşirelerin nöbet tesliminde SBAR teslim formu doldurma oranları nasıldır?

- Hemşirelerin SBAR teslim formuna yönelik geri bildirimleri nasıldır?

\section{Araştırmanın Tipi}

\section{Yöntem}

Araşıtırma, eylem araştırması tasarımında bir çalışmadır.

\section{Araştırmanın Yapıldı̆̆ Yer}

$\mathrm{Bu}$ araştırma, bir üniversite hastanesinin cerrahi ve dahili birimlerinde yürütülmüştür. Araştırma süreci başlamadan önce araştırmanın yürütüldüğü kliniklerde hasta teslimi için farklı formatlarda formlar kullanılmaktaydı. Hasta başında her kliniğe ait teslim formu üzerinden teslim süreci gerçekleştirilmekteydi. Her vardiyada sözlü teslimle hemşireler kendilerine notlar almaktaydı. Bu araştırma ile formlar ve süreç standardize edilmiş oldu.

\section{Araştırmanın Evreni/Örneklemi}

Araştırma, 15 Aralık 2018-15 Eylül 2019 tarihleri arasında gerçekleştirilmiştir. Harvard Üniversitesi Risk Yönetim Vakfi'nın 2015 raporunda, iletişim kaynaklı tıbbi hataların \%27'sinin diğer birimlere göre daha büyük bir payla cerrahi birimlerde olduğu görülmektedir (5). Ülkemizde yapılmış bir çalışmada ise cerrahi kliniklerde çalışan hemşirelerin tıbbi hataya eğiliminin anlamlı olarak yüksek olduğu bulunmuştur (27). Bu nedenle çalışma örneklemine iki cerrahi klinik alınmıştır. Uygulamanın tüm hastaneye yaygınlaştırılabilmesi için üç dahili klinik de örnekleme dahil edilmiştir. Hemşirelik hizmetleri yönetiminin önerisiyle Göğüs-Kalp-Damar Cerrahisi Kliniği, Beyin Cerrahisi Kliniği, Dahiliye 1 Kliniği, Dahiliye 2 Kliniği ve Palyatif Bakım-Aritmi Kliniği’'nde çalışma yürütülmüştür. Örnekleme teslim sürecini gerçekleştiren klinik hemşireleri alınmışıı ( $\mathrm{n}=55$ ) (Tablo 1). Ancak, Tanıtıcı ve Çalışma Durumu Bilgi Formu ile SBAR Geri Bildirim Formunu 50 hemşire doldurmuştur. Ayrıca kliniklerde kullanılan formun değerlendirilmesi de 1410 form üzerinden yapılmıştır.

Tablo 1. Kliniklere Göre Hemşire Dağıllımlart (n=55)

\begin{tabular}{lcc}
\multicolumn{1}{c}{ Klinik Adı } & \multicolumn{2}{c}{ Hemşire } \\
\cline { 2 - 3 } & $\mathrm{n}$ & $\%$ \\
\hline Göğ̈̈s- Kalp-Damar Cerrahisi Kliniği & 13 & 23.6 \\
\hline Beyin Cerrahisi Kliniği & 13 & 23.6 \\
\hline Dahiliye 1 Kliniği & 13 & 23.6 \\
\hline Dahiliye 2 Kliniği & 11 & 20.0 \\
\hline Palyatif Bakım-Aritmi Kliniği & 5 & 9.2 \\
\hline Toplam & 55 & 100 \\
\hline
\end{tabular}

\section{Veri Toplama Araçları}

Araştırmanın verileri, 'Tanıtııı ve Çalışma Durumu Bilgi Formu', 'SBAR Teslim Formu' ve 'SBAR Geri Bildirim Formu' kullanılarak toplanmıştır.

Tanitıcı ve Çalışma Durumu Bilgi Formu

Form, araştırmacı tarafından hazırlanmış ve katılımcının yaşı, cinsiyeti, eğitim durumu, hemşirelik yaptığı süre, çalıştı̆ı birim, birimdeki çalışma süresi, birimdeki görevi ile ilgili yedi sorudan oluşmaktadır.

SBAR Teslim Formu

SBAR teslim formu, alanyazın doğrultusunda SBAR iletişim modeli incelenerek araştırmacı tarafindan yapılandırılmıştır $(28,29)$. Aşağıda SBAR iletişim modeline göre hazırlanmış veri toplama aracının bölümleri ve içeriği yer almaktadır: bilgileri

S (Durum) bölümü, hastanın odası, adı, soyadı, sorumlu doktoru- dış birim ise doktor telefonu, alerji/kol bandı

B (Tıbbi öykü) bölümü, hastanın tanısı, post-op kaçıncı günde olduğu, işlem için aç bekleme durumu, izolasyon endikasyonu, özellikli tedavi-narkotik ilaç teslimi, intravenöz sıvı varlığı

A (Değerlendirme) bölümü, anormal yaşam bulgusu, bilinç düzeyi, beslenme durumu, basınç yarası varlığı, dren/ katater varlığ 1 

önerileri

R (Öneri) bölümü, yaşam bulguları, aldığı/çıkardığı takibi, kan şekeri izlem, masaj-pozisyon girişim sıklık

Formun içerik geçerliliğinde, önce hemşirelik hizmetleri müdürlüğü ve belirlenen kliniklerin sorumlu hemşireleri ile görüsşme yapılmıştır. Yapılan bu ilk toplantıda, araştırmacı ve danışman tarafından konunun önemi, planlanan değişimin nedenleri, SBAR iletişim aracı ve form oluşturulması sürecinde hangi düzenlemelerin gerekli olduğuna dair bilgiler aktarılmıştır. Araştırmacılar tarafından alanyazın doğrultusunda hazırlanan formun, hemşirelik hizmetleri müdürlüğü ve sorumlu hemşirelerden gelen geri bildirimlerle ana yapısı değişmeyecek şekilde düzenlenmesi planlanmış ve sorumlu hemşirelerden klinik hemşirelerinden de görüşlerinin alınması istenmiştir. Tüm geri bildirimlerin tekrar değerlendirilmesi amacıyla bir ay sonra ikinci toplantı gerçekleştirilmiştir.

Yapılan ikinci toplantıya hemşirelik hizmetleri yönetimi, sorumlu hemşireler ve araştırmacılar katılmıştır. Bu toplantıda klinik hemşirelerden sorumlu hemşireler aracilığıyla gelen geri bildirimlere göre düzenlenen form, GöğüsKalp-Damar Cerrahisi Kliniği’nde deneme amaçlı üç ay süreyle kullanılmaya başlanmıştır. Hastanın izleminin hemşirenin klinikten ayrıldığı zamanlarda da yapılabilmesi amacıyla hemşire istasyonunda bulundurulması kararı alınmıştır.

Göğüs-Kalp-Damar Cerrahisi Kliniği’nin görüş ve önerilerini almak ve formun kullanım kolaylı̆̆ını sağlamak için hemşirelik hizmetleri müdürlüğünün de katılım sağladığı üçüncü bir toplantı daha yapılmıştır. Bu toplantıda formu kullanmaya yeni başlayacak dört klinik için de ilk toplantı içeriğinde bilgilendirme yapılmış ve kullanıma başlanmış kliniğin görüş ve geri bildirimleri alınarak süreç ilerlemiştir. Formun arka sayfasına yerleştirilemeyecek bilgiler için notlar kısmı, hemşirelik hizmetleri müdürlüğü önerisiyle eklenmiş̧ir. Diğer dört klinik üç ay, Göğüs-Kalp-Damar Cerrahisi Kliniği altı ay süreyle kullandıktan sonra aylık değerlendirilen kullanım oranlarının düşük olması sebebi ve ara geri bildirim alınması amacıyla dördüncü toplantı planlanmıştır.

Dördüncü toplantıya, kliniklerde çalışan hemşireler de davet edilmiştir. Toplantıda kliniklerden gelen hemşireler ve sorumlu hemşirelerden gelen tüm görüşler alınıp form kliniklerde kullanıma uygun hale getirilmiştir. Yapılan bu son toplantıda kullanım oranlarının arttırılması amacıyla hemşirelerden gelen öneri doğrultusunda daha önce kullandığı gibi formu yanında taşımalarına karar verilmiştir.

Uygulama aşamasında, SBAR teslim formu her nöbet tesliminde kullanılmıştır. Kullanılan toplam form sayısı 1410'dur.Göğüs-kalp-damar cerrahisi kliniğinde üç ay deneme sonrasında altı ay daha kullanıma devam edilmiş ve toplamda dokuz ay boyunca form kullanılmıştır. Diğer klinikler ise form altı ay süreyle kullanılmıştır.

SBAR Geri Bildirim Formu

Hemşirelerin SBAR iletişim aracına uygun hasta teslim formu kullandıktan sonra memnuniyetlerini değerlendirmek üzere SBAR Geri Bildirim Formu kullanılmıştır. Bu form, Demir ve Şahin tarafından 2014 yılında oluşturulmuş olup SBAR aracıyla ilgili görüşleri belirten 11 maddeden ve evet/hayır şeklinde görüş bildirilecek biçimde yapılandırılmıştır (30).

\section{Verilerin Toplanmast}

Araştırmanın gerçekleştirildiği hastanede SBAR teslim formunun, Göğüs-Kalp-Damar Cerrahisi Kliniği’nde üç ay deneme sonrasında altı ay daha kullanımına devam edilmiş ve toplamda dokuz ay boyunca form kullanılmıştır. Diğer klinikler ise formu altı ay süreyle kullanmıştır. Formun uygulandığ 1 sürede, doldurulan tüm formlar araştırmacı tarafından analiz için her ay kliniklerden alınmış ve tek tek değerlendirilmiştir. SBAR geri bildirim formları ise her kliniğe elden verilmiş, doldurulan formlar aynı gün ya da birkaç gün içinde geri alınmıştır.

\section{Verilerin Değerlendirilmesi}

Hemşirelerin tanıtıcı ve çalışma durumu, SBAR teslim formunu kullanım durumları ve hemşirelerin geri bildirim formu verileri SPSS (Statistical Package for the Social Sciences) 16.0 programında sayı, yüzdelik, frekans olarak tanımlayıcı istatistikler kapsamında değerlendirilmiştir. Teslim formunun doldurulma oranları değerlendirilirken deneme yapılan klinik ve diğer kliniklerde kullanılan 1410 form analiz edilmiştir.

\section{Arastırmanın Etik Yönü}

SBAR Geri Bildirim Formu kullanımı için Dr. Öğr. Gör. Sevda DEMİR ve Prof. Dr. Nevin HOTUN ŞAHINN'den yazılı izin, araştırmanın gerçekleştirildiği hastaneden uygulama izni ve etik açıdan ise araştırmanın yapıldığı üniversitenin girişimsel olmayan klinik araştırmalar etik kurulundan izin alınmıştır (Karar Tarihi: 28.05.2018, Karar No: 2018/1331). Çalışmaya katılmayı kabul eden hemşirelerden sözel ve bilgilendirilmiş yazılı onam alınmıştır. Makalenin tüm aşamalarında araştırma ve yayın etiğine uyulmuştur.

Hemşirelerin SBAR teslim formunu kullanım durumları incelendiğinde, klinikler bazında elde edilen veriler Tablo 2'de sunulmuştur.

Deneme yapılan klinik Göğüs-Kalp-Damar Cerrahisi Kliniği, ilk iki ayda kullanım olarak birbirine benzer sonuçlar (\%36.1-34.6) göstermiştir. Üçüncü ay kullanım oranı en düşük (\%17.3), sonraki üç ayda artan oran belirlenmiştir. Dahiliye 2 ve Palyatif Bakım-Aritmi Kliniği'nin üç aylık bulgularının giderek artan oranda olduğu bulunmuştur. Çalışma boyunca kullanımı incelendiğinde, SBAR teslim formunun en yüksek kullanım yüzdesi Palyatif Bakım-Aritmi Kliniği'ndedir. 
Tablo 2. Kliniklere ve Aylara Göre SBAR Teslim Formunun Kullanımı

\begin{tabular}{|c|c|c|c|c|c|c|c|c|c|c|c|c|c|c|c|c|c|c|}
\hline \multirow[b]{2}{*}{ Klinik } & \multicolumn{3}{|c|}{ 1.AY } & \multicolumn{3}{|c|}{ 2.AY } & \multicolumn{3}{|c|}{ 3.AY } & \multicolumn{3}{|c|}{ 4.AY } & \multicolumn{3}{|c|}{ 5.AY } & \multicolumn{3}{|c|}{ 6.AY } \\
\hline & 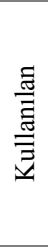 & 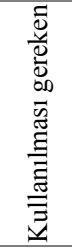 & $\begin{array}{l}\stackrel{\circ}{0} \\
\text { 吾 } \\
\text { 言 } \\
\bar{\Xi} \\
\underline{a}\end{array}$ & 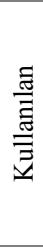 & 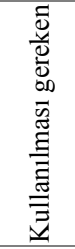 & 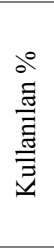 & 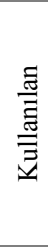 & 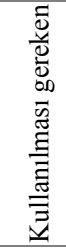 & 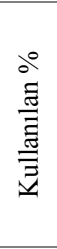 & 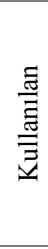 & 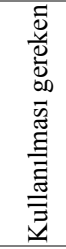 & 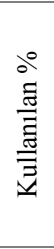 & $\begin{array}{l}\text { 売 } \\
\text { 奇 } \\
\bar{\Xi}\end{array}$ & 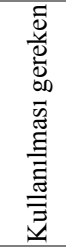 & 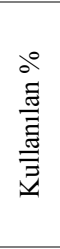 & $\begin{array}{l}\text { 売 } \\
\text { 壳 } \\
\bar{\Xi}\end{array}$ & 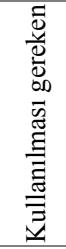 & 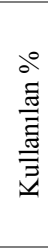 \\
\hline $\begin{array}{l}\text { Göğüs-Kalp- } \\
\text { Damar } \\
\text { Cerrahisi } \\
\text { Kliniği }\end{array}$ & 54 & $\begin{array}{c}20 \\
7\end{array}$ & $\begin{array}{c}26 . \\
0\end{array}$ & 89 & $\begin{array}{c}18 \\
8\end{array}$ & $\begin{array}{c}47 . \\
3\end{array}$ & $\begin{array}{c}11 \\
1\end{array}$ & $\begin{array}{c}20 \\
9\end{array}$ & $\begin{array}{c}53 . \\
1\end{array}$ & 81 & $\begin{array}{c}18 \\
8\end{array}$ & $\begin{array}{c}43 . \\
0\end{array}$ & 50 & $\begin{array}{c}19 \\
3\end{array}$ & $\begin{array}{c}25 . \\
9\end{array}$ & 46 & $\begin{array}{c}15 \\
3\end{array}$ & $\begin{array}{c}30 . \\
0\end{array}$ \\
\hline $\begin{array}{l}\text { Beyin } \\
\text { Cerrahisi } \\
\text { Kliniği }\end{array}$ & 51 & $\begin{array}{c}18 \\
6\end{array}$ & $\begin{array}{c}27 . \\
4\end{array}$ & 23 & $\begin{array}{c}16 \\
8\end{array}$ & $\begin{array}{c}13 . \\
6\end{array}$ & - & $\begin{array}{c}18 \\
6\end{array}$ & 0 & 67 & $\begin{array}{c}16 \\
8\end{array}$ & $\begin{array}{c}39 . \\
8\end{array}$ & - & $\begin{array}{c}17 \\
8\end{array}$ & 0 & - & $\begin{array}{c}13 \\
8\end{array}$ & 0 \\
\hline $\begin{array}{l}\text { Dahiliye-1 } \\
\text { Kliniğgi }\end{array}$ & 15 & $\begin{array}{l}18 \\
6\end{array}$ & 8.0 & 10 & $\begin{array}{c}16 \\
8\end{array}$ & 5.9 & - & $\begin{array}{c}18 \\
6\end{array}$ & 0 & 26 & $\begin{array}{c}16 \\
8\end{array}$ & $\begin{array}{c}15 . \\
4\end{array}$ & 34 & $\begin{array}{c}17 \\
8\end{array}$ & $\begin{array}{c}19 . \\
1\end{array}$ & 23 & $\begin{array}{c}13 \\
8\end{array}$ & $\begin{array}{c}16 . \\
6\end{array}$ \\
\hline $\begin{array}{l}\text { Dahiliye-2 } \\
\text { Kliniği }\end{array}$ & 23 & $\begin{array}{c}15 \\
5\end{array}$ & $\begin{array}{c}14 . \\
8\end{array}$ & 29 & $\begin{array}{c}14 \\
0\end{array}$ & $\begin{array}{c}20 . \\
7\end{array}$ & 60 & $\begin{array}{c}15 \\
5\end{array}$ & $\begin{array}{c}38 . \\
7\end{array}$ & 43 & $\begin{array}{c}14 \\
0\end{array}$ & $\begin{array}{c}30 . \\
7\end{array}$ & 12 & $\begin{array}{c}15 \\
3\end{array}$ & 7.8 & - & $\begin{array}{c}11 \\
5\end{array}$ & 0 \\
\hline $\begin{array}{l}\text { Palyatif } \\
\text { Bakım - } \\
\text { Aritmi Kliniği }\end{array}$ & 38 & $\begin{array}{c}12 \\
4\end{array}$ & $\begin{array}{c}30 . \\
6\end{array}$ & 55 & $\begin{array}{c}11 \\
2\end{array}$ & $\begin{array}{c}49 . \\
1\end{array}$ & 65 & $\begin{array}{c}12 \\
4\end{array}$ & $\begin{array}{c}52 . \\
4\end{array}$ & 48 & 56 & $\begin{array}{c}85 . \\
7\end{array}$ & 37 & 64 & $\begin{array}{c}57 . \\
8\end{array}$ & 21 & 46 & $\begin{array}{r}45 . \\
6\end{array}$ \\
\hline
\end{tabular}

Hemşirelerin SBAR teslim formunun bölümlerini doldurma oranları, kliniklerden toplanan formlar üzerinden incelenmiştir (n=1410). "Durum” bölümünün \%98.9 oranla en çok kullanılan bölüm olduğu görülmektedir. En az kullanılan bölüm "değerlendirme” kısmı olarak bulunmuştur (\%75.8) (Tablo 3).

Tablo 3. SBAR Teslim Formunun İçindeki Bölümlerine Göre Kullanımı (n=1410)

\begin{tabular}{|c|c|c|c|c|}
\hline \multirow{2}{*}{ Bölümler } & \multicolumn{2}{|c|}{ Doldurulan } & \multicolumn{2}{|c|}{ Doldurulmayan } \\
\hline & $\mathbf{n}$ & $\%$ & $\mathbf{n}$ & $\%$ \\
\hline S (Durum) & 1395 & 98.9 & 15 & $\begin{array}{l}1 . \\
0\end{array}$ \\
\hline B (Tıbbi öykü) & 1356 & 96.1 & 54 & $\begin{array}{l}3 . \\
8\end{array}$ \\
\hline A (Değerlendirme) & 1070 & 75.8 & 340 & $\begin{array}{c}24 \\
.1\end{array}$ \\
\hline R (Öneri) & 1291 & 91.5 & 119 & $\begin{array}{l}8 . \\
4\end{array}$ \\
\hline
\end{tabular}

Araştırmaya katılan hemşirelerin SBAR iletişim aracına ilişkin geri bildirimleri altı ay kullanan klinikler ve dokuz ay kullanan klinikler baz alınarak incelenmiştir (Tablo 4). Bu incelemeye, kliniklerde SBAR formunun kullanım sürelerindeki farklılık nedeniyle gereksinim duyulmuştur. Hemşirelerin \%86.4’ü, nöbet tesliminde SBAR iletişim aracının zaman kaybettirdiğini düşündüğünü bildirmiştir. Bu oran dokuz ay kullanan klinikte \%53.8 olarak belirlenmiştir. SBAR iletişim aracı kullanmanın nöbet teslimlerine bir olumlu katkı getirmediğini düşünen hemşire oranı \%86.4 olarak bulunmuş, dokuz ay kullanan klinikte ise bu oranın \%53.8 olduğu saptanmıştır. Hemşirelerin \%59.4'ü ve dokuz ay kullanan klinik hemşirelerinin \%84.6’1 SBAR iletişim aracını kullandığı dönemde hiç istenmeyen (advers) olay yaşamadığını bildirmiştir. Nöbet teslimlerinde SBAR iletişim aracını kullanmaya devam etmek isteyen hemşire oran $1 \% 8.1$ iken; bu oran deneme yapılan klinikte \%46.1 olarak bulunmuştur. 
Tablo 4. Hemşirelerin Kullanım Süresine Göre SBAR Geri Bildirim Sonuçları

\begin{tabular}{|c|c|c|c|c|}
\hline \multirow[t]{2}{*}{ Görüşler } & \multicolumn{2}{|c|}{$\begin{array}{l}\text { Alti Ay Kullanan } \\
\text { Klinikler }\end{array}$} & \multicolumn{2}{|c|}{$\begin{array}{l}\text { Dokuz Ay } \\
\text { Kullanan Klinik }\end{array}$} \\
\hline & Sayı & $\%$ & Sayı & $\%$ \\
\hline 1- SBAR iletişim tekniğini kullanmam çok kolay oldu. & 8 & 21.6 & 5 & 38.4 \\
\hline $\begin{array}{l}\text { 2-SBAR iletişim aracının, istenmeyen (advers) olay yaşanmasını } \\
\text { engelleyeceğini düşünüyorum. }\end{array}$ & 11 & 29.7 & 8 & 61.5 \\
\hline $\begin{array}{l}\text { 3-SBAR iletişim aracı ile hastam hakkında bilgileri eksiksiz ve hızlı bir } \\
\text { şekilde teslim ettiğimi düşünüyorum. }\end{array}$ & 5 & 13.5 & 6 & 46.1 \\
\hline $\begin{array}{l}\text { 4-Nöbet tesliminde SBAR iletişim aracının bana zaman kaybettirdiğini } \\
\text { düşünüyorum. }\end{array}$ & 32 & 86.4 & 7 & 53.8 \\
\hline 5- SBAR iletişim aracı, işimi daha iyi yapmama yardımcı oluyor. & 6 & 16.2 & 6 & 46.1 \\
\hline $\begin{array}{l}\text { 6-Nöbet teslimlerinde SBAR iletişim aracının kullanımı ile ekip içinde } \\
\text { iletişimin daha sağlıklı olduğunu düşünüyorum. }\end{array}$ & 3 & 8.1 & 7 & 53.8 \\
\hline $\begin{array}{l}\text { 7-SBAR iletişim aracını kullanmamız, diğer ekip üyeleri tarafından da } \\
\text { olumlu bulundu. }\end{array}$ & 2 & 5.4 & 5 & 38.4 \\
\hline $\begin{array}{l}\text { 8-SBAR iletişim aracı kullandığım dönemde hiç istenmeyen (advers) } \\
\text { olay yaşamadım. }\end{array}$ & 22 & 59.4 & 11 & 84.6 \\
\hline $\begin{array}{l}\text { 9- SBAR iletişim aracı ile nöbet teslimi diğer ekip üyelerinin de uyum } \\
\text { sağlamasını gerektiriyor. }\end{array}$ & 21 & 56.7 & 9 & 69.2 \\
\hline $\begin{array}{l}\text { 10-SBAR iletişim aracı kullanmak nöbet teslimlerine bir olumlu katkı } \\
\text { getirmedi. }\end{array}$ & 32 & 86.4 & 7 & 53.8 \\
\hline $\begin{array}{l}\text { 11-Nöbet teslimlerinde SBAR iletişim aracını kullanmaya devam etmek } \\
\text { istiyorum. }\end{array}$ & 3 & 8.1 & 6 & 46.1 \\
\hline
\end{tabular}

\section{Tartışma}

Yaptığımız çalışmada, SBAR teslim formunun en fazla Palyatif Bakım-Aritmi Kliniği’nde kullanıldığı belirlenmiştir (Tablo 2). Palyatif Bakım-Aritmi Kliniği’nin sorumlu hemşiresinin değişim ajanı rolü üstlenerek hemşireleri formun kullanımı konusunda motive etmesi, daha önceden teslim için kullandıkları formun olmaması ve yeni forma gereksinimin olması, sorumlu hemşiresinin tepe yöneticilik deneyimi nedeniyle hasta güvenliği ve kalite konularında farkındalığının yüksek olması sonucu kullanım oranı artmış olabilir. Alanyazında değişim sürecinde çalışanları destekleyen bir yönetim varlığı, çalışanların görüş ve önerilerinin alınmasının değişimin uygulanmasında olumlu etki yarattığı vurgulanmaktadır (31,32). Dolayısıyla Palyatif Bakım-Aritmi Kliniği’ndeki kullanım bu yönde açıklanabilir. Formu dokuz ay süreyle kullanan Göğüs-Kalp-Damar Cerrahisi Kliniğinde de kullanım oranının (\%5.1) yüksek olduğu görülmektedir (Tablo 2). Formun toplamda dokuz ay süreyle kullanılmış olmasının, değişim sürecinin adımlarının diğer kliniklere göre biraz daha uzun sürede uygulanmasının etkili olduğu düşünülebilir. Alanyazında değişim sürecinin uzun tutulmasının değişimi kolaylaştırdığı ve direnci azalttığı belirtilmektedir (31). Diğer kliniklerin kullanım oranının istendik düzeyde olmadığı belirlenmiştir (Tablo 2). Hemşirelerin yeni oluşturulan bu formu kullanımlarındaki boşluk, yaşanan hemşire yetersizliğinin bir sonucu olarak düşünülebilir. Ülkemizde görev yapan 166.142 hemşirenin yalnızca 24.261'i üniversite hastanelerinde çalışmaktadır (33). Hasta bakımının güvenli planlanması ve bütüncül sunulması, kliniklerde yeterli sayıda hemşire planlanmasıyla gerçekleşmektedir (34-36). Ayrıca yeni formun kullanım azlığının nedeni, kliniklerde SBAR formunun değişim olarak algılanması ve bu sürecin yönetimi ile de ilişkili olabilir. Yaşanan başarılı değişimlerde, çalışanın da süreçte yer alması, hazır oluşluğu önem taşımaktadır. Hemşirelerin yaşadıkları tükenmişlik ve çalışan eksikliği, değişime karşı direnç geliştirmelerine yol açmış olabilir (37-39). Sağlık kurumlarında planlanan değişimler için hemşirelerin de içinde bulunduğu bir karar ortamı düşünülmeli ve hazır oluşlukları göz önünde bulundurulmalıdır (40). Çalışmada, hemşirelerden ve yöneticilerinden forma duydukları gereksinim, formun içeriği vb. konularda görüş alınarak kullanımı konusunda kararlara katılımı sağlanmaya çalışılmış olsa da, değişsim için gerekli sürenin yaşanmamış olması kullanımın zaman içinde artabileceğini düşündürmektedir. Kullanılan form, hasta güvenliği kültürü ile de ilişkilendirildiğinde, hasta güvenlik kültürünün kurumun her biriminde farklı olabileceği söylenebilir.

SBAR teslim formunun bölümlerine göre doldurulma oranları değerlendirildiğinde, en az kullanımın “değerlendirme” kısmında olduğu görülmektedir (Tablo 3). Hemşirelik mesleğinde zaman yönetimi oldukça önemli bir kavramdır. Formların doldurulmasının özellikle kalite ve hasta güvenliğinde form sayılarının fazla olması nedeniyle zaman alıcı olması tepki yaratan bir konudur (41). Eroğlu ve Özgür (2016)'ün çalışmasında hemşirelerin \%27.9'u hasta ile ilgili formları doldururken zaman kaybettiğini düşündüğünü ifade etmiştir (42). Çalışmamızdaki hemşirelerin kliniklerde kullandıkları farklı teslim formları yerine, yeni geliştirilen SBAR iletişim aracı kullanmalarının zaman açısından fark yaratmayacağı düşünülmektedir. Ancak hasta değerlendirme bilgilerinin hasta gözlem formunda da var olduğunu düşünmeleri nedeniyle yeni formu kullanmaya gereksinim duymadıkları söylenebilir.

Bir başka açıdan değerlendirildiğinde, hemşirelerin SBAR teslim formunun durum, tıbbi öykü ve öneri bölümlerini yüksek oranda doldurduğu görülmüştür (Tablo 3). Araştırmanın uygulandığı tüm klinikler formu yeni kullanmalarına rağmen bölümlerin çoğunu kullanmışlardır. Hemşirelerin aslında teslimlerde bu bilgilere gereksinim duydukları ve hasta bakım planlamalarını kolaylaştırdığı için bu bölümleri doldurdukları düşünülebilir.

Yürütülen bu çalışmada, hemşire geri bildirimleri genel anlamda olumsuz bulunmuştur. Hemşirelerin büyük çoğunluğu (\%86.4) nöbet tesliminde SBAR iletişim aracının zaman kaybettirdiğini düşünmüştür. Deneme yapılan klinik 
hemşirelerinde sonuç benzerlik gösterse de bu oranın daha düşük (\%53.8) olduğu görülmüşsür (Tablo 4). Yapılmış çalışmalar incelendiğinde, SBAR iletişim aracı ile hemşire teslimlerinin daha kısa sürede tamamlandığı görülmektedir $(15,43)$. Cornell ve ark. (2014)'nın yaptıkları çalışmada hasta teslim süresinin belirgin şekilde kısaldığı, $53 \mathrm{dk}$ olan teslim süresinin $45.1 \mathrm{dk}$ ya düştüğü sonucu elde edilmiştir (43). Ancak diğer bazı çalışmalarda teslim süresinin değişmediği (16); bazı çalışmalarda ise uzadığı sonucuna varılmıştır (44). Bu çalışmada formun kullanım süresi dakika olarak değerlendirilmemesine rağmen, hemşireler formun kendilerine zaman kaybettirdiği algısı ile sürenin fazla olduğunu düşünüyor olabilirler.

Araştırmaya katılan hemşirelerin \%86.4'ünün SBAR iletişim aracı kullanmanın nöbet teslimlerine olumlu bir katkı getirmediğini düşündükleri belirlenmiştir. Deneme yapılan klinikte bu oranın daha düşük $(\% 53.8)$ olduğu görülmektedir (Tablo 4). Hemşirelerin nöbet teslimlerinde kendi yaptıkları ve gelecek vardiyada yapılacakları aktarma yönünde bir form kullanmış olmaları, yeni forma uyumun zorlukları ve değişime uyum açısından yeterli sürenin geçmemiş olması SBAR iletişim aracının getirdiği katkının farkındalığını olumsuz yönde etkilemiş olabilir $(39,40)$.

Çalışmaya katılan hemşirelerin büyük çoğunluğu SBAR iletişim aracının istenmeyen (advers) olay yaşanmasını engelleyeceğini düşünme oranı \%29.7 olmasına rağmen, \%59.4'ü 'SBAR iletişim aracı kullandığım dönemde hiç istenmeyen olay yaşamadım' ifadesini kullanmıștır. Bu oranlar, deneme yapılan klinikte daha yüksek bulunmuş̧tur (Tablo 4). Fabila, Hee ve ark. (2017) yaptıkları çalışmada, SBAR'ın özellikle sözel iletişimde yaşanacak tıbbi hataları engellediği belirlenmiştir (45). Ulaşılan birçok çalışmada da SBAR iletişim aracının tıbbi hataları azalttığı ve hemşirelerin bu konudaki görüşlerinin de azalma yönünde olduğu belirlenmiştir $(15,17,46)$. Dolayısıyla çalışma sonuçları alanyazınla benzerlik göstermemektedir. Çalışmanın yapıldığı kurumda, istenmeyen olay bildirim sayıları yetersiz olduğundan ve kök neden çalışmalarının iletişim hatalarından kaynaklı hata verilerini sunmadığından, hemşirelerin bu yöndeki farkındalıklarının yeterli olmadığı, sonuç olarak geri bildirimlerinin de istenmeyen olayları azaltacak bir yöntem olmadı̆̆ yönünde olduğu söylenebilir.

Çalışmaya katılan hemşirelerin \%8.1'i nöbet teslimlerinde SBAR iletişim aracını kullanmaya devam etmek istediklerini ifade etmişlerdir. Deneme yapılan klinik hemşireleri kullanıma belirgin farkla devam etmek istemiştir (Tablo 4). Dünyada yapılmış çalışma sonuçları, kullanım sonrasında çalışan memnuniyetinin arttığını göstermektedir $(15,47,48)$. Demir ve Şahin (2014)'in yaptıkları çalışmanın sonucuna göre ise; hemşirelerin genel olarak memnun olduğu ancak \%57.1'nin kullanmaya devam etmek istemediği belirtilmiştir (30). Çalışmamızın sonuçlarının alanyazınla benzerlik göstermemesinin nedeni, gerekli değişim için sürenin yeterli olmadığı yönünde düşünülebilir. Ayrıca dokuz ay kullanan ve altı ay kullanan kliniklerin bulguları (Tablo 4) değerlendirildiğinde, hemşirelerden alınan tüm geri bildirim maddelerinde dokuz ay kullanan kliniğin bulgularının daha olumlu olduğu belirtilmektedir. Bu sonucun değişim sürecinin yönetildiği sürenin üç ay bile olsa kısa bir zaman farkı ile değerlendirilmesinin, olumlu sonuç ve geri bildirimlerle karşımıza çıkabileceğini göstermiş olabileceği yönündedir $(31,32,49,50)$.

\section{Kisitlılıklar}

Klinik uygulama sürecinde, nöbet teslimleri gözlenmediği için formun kullanımına ilişkin veriler aylık olarak toplanan SBAR teslim formlarının işaretlenmesinden elde edilmiştir. Ayrıca klinik uygulama sürecinin değişim açısından kısa olması ve teslim sürecinin dakika olarak değerlendirilmemesi de kısıtlılık olarak değerlendirilebilir.

\section{Sonuçların Uygulamada Kullanımı}

Ülkemizde iletişime bağlı tıbbi hataların en çok yaşandığı birimler cerrahi birimlerdir. Hasta teslimleri, hemşire-hemşire iletişiminde önemli bir paya sahiptir. Teslim sürecinde SBAR iletişim aracının kullanılması hasta bilgilerinin tam ve eksiksiz iletilmesinde önemli bir araçtır. Ülkemizde, hemşire iş yükünün artması, artan yorgunlukla birlikte iş doyumunun azalması, olumsuz çalışma koşulları nedeniyle hasta teslimlerinde iletişim aracı kullanılması kesintiye uğrayabilmektedir, bu nedenle birim ve tepe yöneticilerin hasta güvenliğinde etkili iletişimi sağlayabilmek için SBAR gibi standardize edilmiş iletişim araçlarını kullanmaları ve hemşireleri bu yönde cesaretlendirmeleri yararlı olacaktır. $\mathrm{Bu}$ uygulama iletişim kaynaklı tıbbi hata oranlarının azaltılmasına da katkı sağlayacaktır. Ayrıca hemşirelerin standardize edilmiş teslim formlarını kullanmaları yönünde eğitimler verilmeli ve sürecin başta zorlayıcı olabileceği anncak sonucunda hem hastayı hem de çalışanı koruyucu bir yöntemin kalıcılığının sağlanabileceği ynünde bir değişim süreci başlatılmalıdır. Hemşire yöneticilere ve kurum yöneticilerine güvenli iletişimin sağlanması için teslim sürecinin önemi ile ilgili düzenli eğitimlerin planlanması, hasta güvenlik kültürü hakkında farkındalığın arttırılması için çalışmaların yapılması ve profesyonel iletişim tekniği kullanımının sağlanması önerilebilir.

\section{Bilgilendirme}

Araştırma için herhangi bir firmadan veya projeden fon desteği alınmamış ve araştırmanın bütçesi araştırmacılar tarafından karşılanmıştır. Araştırmacılar arasında herhangi bir çıkar çatışması bulunmamaktadır. Yazarların araştırmaya katkı oranı beyanları şu şekildedir; araştırmanın konusu ve metodolojisinin belirlenmesi ŞSİ, GC; verilerin toplanması ve işlenmesi GC; verilerin değerlendirilmesi ŞSİ, GC; makalenin yazılması GC, ŞSì. Araştırmanın yapıldığı üniversitenin girişimsel olmayan klinik araştırmalar etik kurulundan izin alınmıştır (Karar Tarihi: 28.05.2018, Karar No: 2018/13-31). 
Kaynaklar

1. WHO Patient safety solutions (Volume 1 Solution 3) 2007. (Erişim Tarihi: 28.01.2018). http://www.who.int/patientsafety/solutions/patientsafety/PSSolution3.pdf?ua=1

2. Özkan A, Kömürcü N. Hasta güvenliği önlemlerinin perinatal kliniklere uyarlanması ve uygulama rehberlerinin geliştirilmesi. Zeynep Kamil Tıp Bülteni. 2012; 43(3):90-96.

3. Ross J. Effective communication improves patient safety. Journal of PeriAnesthesia Nursing, 2018; 33(2): 223225.

4. JCI- Joint Commission International. Sentinel event data: Root causes by event type, 2015. http://www.jointcommission.org/assets/1/18/Root_Causes_Event_Type_2004-3Q_2015.pdf(Erişim Tarihi: 02.02.2018)

5. CRICO Strategies National CBS Report. Malpractice risks in communication failures (2015).

6. T.C. Sağlık Bakanlığı Sağlık Hizmetleri Genel Müdürlüğü Sağlıkta Kalite ve Akreditasyon Daire Başkanlı̆̆ı. SKS Işığında Sağlıkta Kalite. 1. Basım. Ankara Pozitif Matbaa; 2012: 144-150.

7. T.C Sağlık Bakanlığı. 2016 yılı İstatistik ve Analiz Raporu; 2016. (Erişim Tarihi: 15.01.2018)https://grs.saglik.gov.tr/BM/Reports/GRS2016Rapor_R1.pdf

8. JCI- Joint Commission International. National Patient Safety Goals Effective January 1, 2015. http://www.jointcommission.org/assets/1/6/2015_NPSG_HAP.pdf.

9. WHO. Evaluation of the WHO patient safety solutions aides memoir; 2011. (Erişim Tarihi:15.01.2018) http://www.who.int/patientsafety/implementation/solutions/patientsafety/PSP_H5-Solutions_Report-fnlsumry_Apr-2012.pdf

10. Starmer AJ, Sectish TC, Simon DW, et al. Rates of medical errors and preventable advserse events among hospitalized children following implementation of a resident handoff bundle. Jama, 2013; 310(21): 2262-70.

11. Tuğrul E, Khorshid L. Hemşirelerin önemli işlevlerinden biri: Hasta teslimi. Ege Üniversitesi Hemşirelik Fakültesi Dergisi. 2015; 31(1): 95-107.

12. Yeh J, DeName K. Patient handoffs in obstetrics and gynecology: A vital link in patient safety. Clinical Medicine: Women's Health 2009; 2:17-27.

13. Botwinick L, Bisognano M, Haraden C. Leadership Guide to Patient Safety. IHI Innovation Series white paper. Cambridge, Massachusetts: Institute for Healthcare Improvement; 2006. (Erişim Tarihi: 19.01.2018)www.ihi.org

14. Alcan Z, Tekin DE, Özbucak Civil S. Hasta Güvenliği: Beklenmedik olaylarda hemşirenin rolü. 1. Basım. İstanbul Nobel Matbaacilik; 2012: 169-187.

15. Nagammal S, Nashwan AJ, Nair S.LK, Susmitha A. Nurses' perceptions regarding using the SBAR tool for handoff communication in a tertiary cancer center in Qatar. J Nurs Educ Pract. 2017; 7(4):103-110.

16. Funk E, Taicher B, Thompson J, Iannello K, Morgan B, Hawks S. Structured handover in the pediatric postanesthesia care unit. J Perianesth Nurs. 2016;31(1):63-72.

17. Randmaa M, Martensson G, Leo Swenne C, et al. SBAR improves communication and safety climate and decreases incident reports due to communication errors in an anaesthetic clinic: a prospective intervention study. Bmjopen, 2014;4(1):1-8

18. Sears K, Lewis S.T, Craddock M.M, Flowers B.R, Bovie L.C. The evaluation of a communication tool within an acute healthcare organization. Journal of Hospital Administration, 2014; 3(5):79-88.

19. Sherman J, Sand-Jecklin K, Jhonson J. Investigatingbedside nursing report: a synthesis ofthe literature. Medsurg Nurs. 2013;22(5):308-312.

20. De Meester K, Verspuy M, Monsieursa KG, Van Bogaerta P. SBAR improves nurse-physician communication and reduces unexpected death: A pre and post intervention study. Resuscitation, 2013; 84(9):1192-1196.

21. Riesenberg L, Leitzsch, L, Brian W. Systematic review of handoff mnemonics literature. American Journal of Medical Quality. 2009; 24(3):196-204.

22. James D, Jukkala A, Azuero A, Auutrey P, Vining L, Miltner R. Development of the medical intensive care unit shift report communication scale as a measure of nurses' perception of communication. Nursing: Research and Review, 2013;3:59-65.

23. Rykse, M.L. Evidence Based Protocol: Standardizing Handoff to Improve Outcomes, 2017. Oalster, EBSCOhost (Erişim tarihi: 22.01. 2018).

24. Beckett C, Kipnis G. Collaborative communication: integrating SBAR to improve quality/patient safety outcomes. Journal for Healthcare Quality, 2009;31(5): 19-28.

25. Blom L, Petersson P, Hagell P, Westergren A. The situation, background, assessment and recommendation (SBAR) model for communication between health care professionals: A clinical intervention pilot study.International Journal of Caring Sciences, 2015; 8(3):530-535.

26. O'Connell B, Ockerby C, Hawkins, M. Construct validity and reliability of the Handover Evaluation Scale. Journal of Clinical Nursing. 2014; 3(3-4): 560-570.

27. Dikmen Demir Y, Yorgun S, Yeşilçam N. Hemşirelerin tıbbi hata eğilimlerinin belirlenmesi. Hacettepe Üniversitesi Hemşirelik Fakültesi Dergisi, 2014; 1(1): 44-56.

28. NHS Institute for Innovation and Improvement. SBAR - Situation-Background-Assessment-Recommendation. 2008 (Erişim Tarihi:03.03.2018)https://qi.elft.nhs.uk/resource/sbar-situation-background-assessmentrecommendation/

29. Klee K, Latta L, Davis-Kirsch S, Pecchia M. Using continuous process improvement methodology to standardize nursing handoff communication. Journal of Pediatric Nursing, 2012; 27(2):168-173. 
30. Demir S, Şahin Hotun N.Kadın hastalıkları ve doğum kliniklerinde hasta tesliminde SBAR iletişim tekniğinin kullanımı ve hemşire/ebelerin görüşlerinin belirlenmesi. Sağlık Akademisyenleri Dergisi, 2014; 1(2):99-105.

31. Seren, Ş. Baykal, Ü. Kalite belgesi alan hastanelerde örgüt kültürü ve değişime karşı tutumun incelenmesi. Atatürk Üniversitesi Hemşirelik Yüksekokulu Dergisi, 2007; 10(2):1-11.

32. Ulusoy, H. Değiş̧imin Yönetimi, Hemşirelik Hizmetleri Yönetimi. 2014,275-285.

33. T.C. Sağlık Bakanlığı Sağlık Araştırmaları Genel Müdürlüğü Sağlık İstatistikleri Yıllığı 2017.Ankara Kuban Matbaacılık ve Yayınc1lı; 2018: 1-288.

34. Hurst,K. Does poor staffing affect job satisfaction and patient care? Nursing Standart, 2009;23(38),14-18.

35. Cheraghi MA, Salasli M, Ahmadi F. Factors influencing the clinical preparation of BS nursing student interns in Iran. International Journal of Nursing Practice, 2008; 14(1):26-33.

36. Rafii, F., Hajinezhad, ME., Haghani, H. Nurse caring in Iran and its relationship with patient satisfaction. Austrian Journal of Advanced Nursing. 2008; 26(2),75-84.

37. Mrayyan M. Nurses' view of organizational readiness for change. Nursing Forum 2019;54(1)1-9.

38. Hee OC, Cheng TY, Ping, LL, Kowang TO, Fei GC. Embracing change management strategies in bedside shift report (BSR): A Review. International Journal of Academic Research in Business and Social Sciences, 2019;9(1):469-481.

39. Derin T, Demirel Y. Tükenmişlik sendromunun örgütsel bağlılığı zayıflatıcı etkilerinin Malatya Merkez'de görev yapan hemşireler üzerinde incelenmesi. Süleyman Demirel Üniversitesi İktisadi ve İdari Bilimler Fakültesi Dergisi, 2012;17(2):509-30.

40. Bowers B. Managing change by empowering staff. Nursing Times, 2011;107(32/33):17-19.

41. Sönmez MO, Nazik F, Turkol E, Dağ Ş. Bir kamu hastanesinde hemşireler tarafından tutulan yazılı kayıtlar ve hemşirelik hizmetleri ile ilgisi. Hemşirelikte Eğitim ve Araştırma Dergisi, 2014;11(1):34-40.

42. Eroğlu S, Özgür G. Bir üniversite hastanesinde çalışan servis ve yoğun bakım hemşirelerinde zaman yönetimi. Gümüşhane Üniversitesi Sağlık Bilimleri Dergisi. 2016;5(1):12-22.

43. Cornell P, Gervis MT, Yates L, et al. Impact of SBAR on nurse shift reports and staff rounding. Medsurg Nursing. 2014;23(5):334-42.

44. McCrory MC, Aboumatar H, Custer JW, Yang CP, Hunt EA. “ABC-SBAR”training improves simulated critical patient hand-off by pediatric interns.Pediatric Emergency Care. 2012;28(6):538-43.

45. Fabila TS, Hee HI, Sultana R, Assam PN, Kiew A, Chan YH. Improving postoperative handover from anaesthetists to non-anaesthetists in a children's intensive care unit: the receiver's perception. Singapore Medical Journal. 2016;57(5):242-53.

46. Haig KM, Sutton S, Whittington J. National Patient Safety Goals.SBAR: a shared mental model for improving communication betweenclinicians. The Joint Commission Journal On Quality And Patient Safety. 2006;32(3):16775.

47. Manias T, Tomlinson J. Implementation and evaluation of the sbartool in the communication between medical staff in obstetrics. Archives of Disease in Childhood-Fetal and Neonatal Edition. 2011;96:Fa131.

48. Landau S, Wellman LG. Small changes can streamline the handoff process in a staff-driven process improvement project. Journal of Obstetric, Gynecologic \& Neonatal Nursing. 2014;43(Suppl 1):S49.

49. Altındiş $M$, Altındiş S, Saylı H. Sağlık profesyonellerinin değişim sürecindeki tutumlarını belirlemeye yönelik bir araştırma. ZKÜ Sosyal Bilimler Dergisi, 2011;7(14):75-94.

50. Mitchell G. Selecting the best theory to implement planned change. Nursing Management. 2013;20(1):32-37. 